\title{
EFEITOS DA LASERTERAPIA DE BAIXA INTENSIDADE E EXTRATOS VEGETAIS NO PROCESSO DE REPARO TECIDUAL: REVISÃO INTEGRATIVA
}

\author{
Moisés Lopes Carvalho ${ }^{1}$ \\ Ana Paula Pinto ${ }^{2}$ \\ Laís Mayara Machado de Amorim ${ }^{3}$ \\ Francielzo Ferreira Lima ${ }^{4}$ \\ Moacira Lopes Carvalho ${ }^{5}$ \\ Renata Amadei Nicolau ${ }^{6}$
}

Resumo: Na prática clínica a Laserterapia de Baixa Intensidade (LBI) tem sido usada para promover o alívio da dor, a ação anti-inflamatória, e para acelerar o processo de cicatrização em casos de lesão por queimaduras, feridas cirúrgicas e úlceras crônicas. Além da $L B I$, diversos tipos de extratos vegetais na forma hidroalcoólica ou óleo essencial, também são usadas para estimular a nutrição de células, a regeneração de tecidos e promover a velocidade de cicatrização de feridas. Neste estudo buscou-se evidências que comparasse ou associasse os efeitos da LBI à óleos ou extratos vegetais no processo de cicatrização de feridas. Utilizou-se como metodologia a revisão integrativa. Na análise dos artigos, foram identificados 36 artigos, entretanto após adotar os critérios de inclusão descritos na metodologia, restaram apenas três artigos, sendo duas pesquisas que compararam os efeitos da LBI com o extrato hidroalcoólico uma que analisou a atividade das duas terapias, utilizando o extrato das folhas da Solidago chilensis e a irradiação com laser. Conclui-se que utilização a da LBI e os extratos vegetais, isoladamente, mostram-se efetivas durante o processo de reparo tecidual.

Palavras-chave: Terapia a laser de baixa intensidade; Óleos de plantas; Extratos vegetais; Plantas medicinais.

\footnotetext{
1 Universidade do Vale do Paraíba - UNIVAP, Brasil. E-mail: moises.l.carvalho@hotmail.com.

2 Universidade do Vale do Paraíba - UNIVAP, Brasil. E-mail: apaula@outlook.com.br.

3 Universidade do Vale do Paraíba - UNIVAP, Brasil. E-mail: laisinha-16@hotmail.com.

${ }^{4}$ Centro Universitário UNINOVAFAPI/Radiologia/Enfermagem, Brasil. E-mail: francielzolima@hotmail.com.

5 Universidade do Vale do Paraíba - UNIVAP, Brasil. E-mail: moarabb@hotmail.com.

6 Universidade do Vale do Paraíba - UNIVAP, Brasil. E-mail: rani@univap.br.
} 